\title{
The Role of Intentional Communities to Support Recovery from Mental IIIness
}

\author{
Francesca Pernice-Duca, Wendy Case and Deborah Conrad-Garrisi \\ Wayne State University, \\ USA
}

\section{Introduction}

Establishing "community" decreases isolation and social stigma and supports both physical and mental well-being (Ralph \& Corrigan, 2005) for many individuals marginalized by the consequences of a mental illness. This chapter will focus on the role of intentional recovery communities in supporting wellness among people living with mental illness. The chapter will introduce the reader to the concept of recovery from mental illness, a broad variety of approaches designed to facilitate and support recovery as well as recovery oriented environments such as clubhouse programs, peer-run drop-in centers, and peer support groups (e.g., Schizophrenia Anonymous, 12-Step). For example, The FRIENDS program, which is based on the philosophy that social networks evolve from building a strong caring intentional community, has been found to increase and maintain social networks over time to impact overall functioning (Wilson, Flanagan, \& Rynders, 1999). Thus, the central values of many peer- based recovery communities recognize that mental health well-being has a direct relationship to the involvement with others. Therapeutic communities constitute an important aspect in the treatment of mental illness and substance abuse disorders. These 'bottom-up' approaches have a long history as adjunctive services to psychotherapy and psychiatry and provide a valuable, if not essential, component for many seeking recovery from mental illness and substance related disorders.

Mental illness can have devastating effects on an individual's family and social relationships. Individuals with chronic or persistent mental illness can experience the loss of support from friends, family or partners, resulting in small or restricted social support resources. Small social support networks have been associated with mental health concerns such as isolation (Brewer, Gadsden, \& Scrimshaw, 1994), and an increased likelihood of depression (Lin, Ye, \& Ensel, 1999). Poor or inadequate social support networks have also been associated with increased mortality rates among the general population (Berkman, 1995; Berkman, Glass, Brissette, \& Seeman, 2000; House, Landis, \& Umberson, 1988). One of the earliest research studies on social networks and mental health began with Emile Durkheim's empirical examination on the effects of the lack of social network ties and community integration and the rate of suicide in metropolitan areas (see Durkheim, 2001). Between 1969 and 1985, the interest in social network and mental health research proliferated with over 1,300 published research articles (Biegel, McCardel, \& Mendelson, 1985).

Social support networks among people living with severe or chronic mental illness such as schizophrenia, are typically small, and predominately consist of family members or mental 
health professionals (Davidson, Hoge, Merrill, Rakfeldt, \& Griffith, 1995; Goldberg, Rollins, \& Lehman, 2003; Hardiman \& Segal, 2003; Perese, Getty, \& Wooldridge, 2003). Research has shown that small or restricted social networks threaten psychological and emotional wellbeing (Green, Hayes, Dickinson, Whittaker, \& Gilheany, 2002), quality of life (Tempier, Caron, Mercier, \& Leouffre, 1998), and increase the likelihood of psychiatric re-hospitalization (Goldberg, Rollins, \& Lehman, 2003). Cut-off or estranged family relationships have also been correlated with increased psychological distress and functional impairments (Doane, 1991; Fisk, Rowe, Laub, Calvocoressi, \& DeMino, 2000; Froland, Brodsky, Olson, \& Stewart, 2000). Individuals living with chronic and persistent mental illness experience functional impairments in daily living skills and social skills. These impairments can negatively impact social opportunities. Traditional medical model approaches continue to view these negative consequences of serious mental illness as inevitable, which can result in a loss of hope, despair, and chronic grief. The notion of recovery from mental illness has received increasing attention in the mental health field in the last decade. Emerging evidence indicates that social network supports play a significant role in the experiences of recovery from mental illness (Corrigan, \& Phelan, 2004). State and Federal mental health organizations are beginning to recommend recovery oriented practices in the treatment of mental illness, emphasizing the importance of social ties as an integral part of the recovery process (Hogan, 2003). Longitudinal studies spanning the last 30 years have documented recovery from serious mental illness, such as schizophrenia (DeSisto, Harding, McCormick, Ashikaga \& Brooks, 1999; Harding, Brooks, Ashikaga, \& Strauss, 1987a; 1987b). These longitudinal studies challenge traditionally held beliefs about chronic mental illness, and provide support for programs that increase social and vocational opportunities.

\section{Peer support and recovery communities}

The value of peer support is articulated succinctly in the words of John Woodman, a military veteran and resident of the Gordon H. Mansfield Veterans Community in Massachusetts: "[We are] like a band of brothers who have a natural affection for each other. We've seen things nobody should see" (Abrahms, 2011). Those who live with mental illness, addiction, PTSD and other psychiatric health challenges often inherit the burden of isolation, exclusion and stigmatization (Kelly \& Gamble, 2005). Limited options for treatment and a mistrust of the system can hamper recovery efforts (Littrell \& Beck, 2001), as can cultural bias and culturalbound resistance to treatment (Landrine, 1992). Studies have shown that the more socially isolated a person is, the more likely he or she is to experience negative outcomes (Stahler, Shipley, Bartelt, DuCette , \& Shandler, 1995). Structured social support functions not only to unite individuals in a common social network, but also to provide them with positive social influence. A sense of purpose and the dignity of 'belonging' can serve as the catalyst to motivate an individual toward pro-social behaviors that enhance self-care (Kawachi \& Berkman, 2001). Participating in household chores and recreational opportunities can also help clients to become active participants in their lives and recoveries -- making choices and decisions that directly affect their day-to-day existence. This helps them move beyond the conventional treatment model of passively adjusting to their circumstances and into actively engaging with and acknowledging their strengths and limitations (Ridgway, 2001). In addition, peer networks and peer-provided services have been shown to be as effective at relieving symptoms and improving quality of life as non peer-provided support (Solomon, 2004). Paraprofessionals are not only able to relate to those they serve, they have the capability 
to act as a conduit to mental health providers -- providing trusted support for peers who may be at a lower-functioning stage of recovery.

The peer principle is based on the shared experiences and values characterized by mutuality and reciprocity -- that is, peer relationships implies equality (Clay, 2005). Peer support services and programs are designed and delivered by people who have both experienced a mental health disorder and/or recovery from a substance use disorder. These services go beyond the traditional treatment setting of the "clinical office" and extend into a community of people seeking to achieve or sustain their recovery. Peer support programs provide individuals with non-hierarchical relationships that support goals and recovery from mental health and/or substance abuse disorders, which is a significant departure from hierarchical relationships often found in the medical model between physicians and their patients. According to mental health services researchers Davidson et al., (2006) defines peer support as support provided to a mental health or substance abuse service recipient, from a peer in recovery working with another peer who is beginning their recovery journey. Peer support, in its purest fashion, involves an "asymmetrical relationship with at least one designated service/support provider and at least one designated support recipient (Davidson, et al., 2006, p.2)."

Peer support also involves social support, such as providing emotional, informational, instrumental, and affiliation support. Emotional peer support involves demonstrating empathy, caring, and bolstering confidence. Informational support includes sharing knowledge and information about community resources, housing supports, parenting classes or information about wellness and recovery. Concrete assistance, such as helping others to accomplish tasks is often referred to as instrumental support, whereas affiliation support links people to others who share similar experiences in mental health and substance use recovery. Affiliation support includes opportunities to socialize, to engage in a 'recovery community' and to acquire a sense of belonging.

Involvement in a peer support program has been positively correlated with higher appraisals of social support, greater involvement in external community activities, and improved quality of life over time (Nelson \& Lomotey, 2006). Individuals often report that joining peer support programs provide a sense of belonging, which supplants loneliness and isolation (Clay, 2005, p.13) and offers an opportunity to utilize peer support (Shutt, 2009). However, simply 'being peers' does not automatically translate into 'peer support'. Recipients of peer support describe peer support as an adjustment and developmental process. New members may experience feelings of vulnerability of entering a new community and thus may have an adjustment period before engaging with others (Mead, Hilton \& Curtis, 2001). In a qualitative study involving recipients of peer support, this process involves developing trust, withholding information, and connecting with peers who appear to have achieved a higher level of wellness then that of themselves (CoatsworthPuspoky, Forchuk, \& Ward-Griffin, 2006). This may also serve to increase self-esteem and decrease perceived self-stigma of living with a mental illness since connecting with others who are similar to themselves or have achieved a greater level of recovery provide a model for wellness (Verhaeghe, et. al., 2008).

The drive to pursue a greater understanding of the potential for recovery from serious mental illness emerged from consumers of mental health and psychiatric services, public health policies, and data from longitudinal studies. Research suggests that recovery occurs among many people suffering with debilitating psychiatric illnesses (Davidson, et al., 2007; Onken, Craig, Ridgway, Ralph, \& Cook, 2007). Recovery has been studied as a subjective experience through qualitative studies (Deegan, 1988; 2003), as well as an objective outcome measuring level of functioning and the absence of symptoms (Harding et al., 1987a). 
Subjective accounts have described recovery from mental illness as "reawakening of hope from despair; breaking through denial and achieving understanding and acceptance; moving from withdrawal to engagement and becoming an active participant in life; it is active coping rather than passive adjustment (Beale \& Lambric, 1995, p. 5)." Recovery oriented philosophy in mental health has revolutionized service delivery options, including more peer support programs and psychosocial psychiatric rehabilitation.

A crucial part of recovery is the support of a social network of people who believe in the capacities and the strength of the individual challenged or impaired by a psychiatric disability. Family members are often primary caregivers of people living with a serious mental illness and experience the caregiver burden at a higher rate than other types of chronic conditions (Hatfield \& Lefley, 1987, 1993). Cross-cultural studies among people living with schizophrenia revealed differences in recovery rates due to familial connections. In Calabrese and Corrigan's (2005) review of the World Health Organization's cross-cultural research on schizophrenia, the author's noted that individuals living in developing countries were $30 \%$ more likely to meet recovery criteria from schizophrenia than those living in more industrialized countries like Germany or the United States. The authors contend that cultures in developing countries place greater importance on maintaining family and social relationships and social roles (e.g., teacher, mother, worker), while Western cultures tend to place greater emphasis on autonomy from the nuclear family and de-emphasize the importance of extended family members. The role of the community support movement in the U.S. provided families and former mental hospital patients more opportunities for recovery in the community. The goal of intentional recovery communities, such as clubhouses, is to provide individuals with alternative sources of support and to promote independence and recovery.

The extent to which programs nurture hope has been commonly reported by consumers as encouraging recovery (Young \& Ensing, 1999). Successful recovery neither erases traumatizing experiences from memory, nor does it necessarily eliminate symptoms. Rather, successful recovery simply means that the person has adapted to new perspectives of himself and his world (Jacobson \& Curtis, 2002; Ridgway, 2001). The experiences of the illness, while still important, are no longer the primary focus of the person's life (Anthony, 1993). The National Consensus Statement on Mental Health Recovery outlines ten components related to the process of recovery which reflect both aspects of the person and recovery environment (U.S. Department of Health and Human Services, 2006). Described as an essential value of the recovery process, self-direction is characterized as leading, controlling, or exercising choice over and determining one's own path of recovery by optimizing autonomy, independence, and control of resources. Environments that emphasize individualized and person-centered planning provide multiple pathways to the recovery process based on the unique strengths and resiliencies of the consumer. Empowerment is described as the authority to choose from a range of treatment and service options as well as to participate in all decisions that will affect the life of the consumer. Holistic services encompass important aspects of the consumer's life by recognizing the interplay between mind, body, spirit, and community. This awareness not only pertains to supporting physical and mental health needs, but also to housing issues, employment, education, spirituality, and opportunities for social connection. As part of holistic approaches, the larger community also recognizes it "play[s] a crucial role in creating meaningful opportunities and roles for consumers (U.S. Department of Health and Human Services, 2006)." Recovery services and environments recognize the non-linear process of recovery which "is not a step-by step process but one based on continual growth, occasional setbacks, and learning from experience" (U.S. Department of Health and Human Services, 2006) 


\section{Brief history of development of therapeutic recovery communities}

The history of psychiatric hospitalization in the United States supported the notion of very limited social status and obligation and created environments in which the individual's autonomy was stripped away through supervised institutional care, closed and locked psychiatric wards and limiting adult rights and duties (Whitakar, 2002). The deinstitutionalization movement occurred as the result of the passage of several governmental acts (e.g., Barden-Lafollette Act, 1943; National Mental Health Act, 1946) which required federal and state governments to provide rehabilitation and vocational services to individuals with serious mental illness in outpatient treatment centers (Accordino \& Hunt, 2001). During the late 1950's numerous studies were conducted by the National Institute of Mental Health (NIMH) and the Joint Commission on Mental Illness and Health that ultimately led to recommendations to increase the understanding of treatment, improve training of professionals, and enhance treatment services for individuals with serious mental illness (Accordino, et al., 2001). The 1960s saw further support of deinstitutionalization as well as protecting the civil rights of individuals with serious mental illness with the passing of the Community Mental Health Act (1963), which supported treatment in least restrictive environments (Accordino et al., 2001). During this time, consumers of mental health services became more vocal and active in the treatment and care they received, thus inspiring a movement in the delivery of psychiatric services to attend to consumer strengths, natural supports, and decrease social isolation (Davidson, et al., 2007; Drake, 2005; Resnick, Fontana, Lehman, \& Rosenheck, 2005).

Rationale supporting the development of intentional communities for people living with mental illness stems from a number of psychological and socio-cultural positions, for instance, as pioneers in this area, Fairweather and Onaga (1993) emphasized the developmental incongruences among the statuses of those with mental illness and those without. They note that social rights and obligations increase as humans move from childhood through adolescence and eventually adulthood. In the absence of coming from a family history of wealth and power, most Americans are able to achieve "personal power, increased income, and prestige" through attaining education and skilled employment (Fairweather \& Onaga, 1993, p. 4). However, because of deviation from accepted societal norms and behaviors, people living with a mental illness have greater challenges in achieving a socially equitable status in society and following a developmental trajectory comparable to their counterparts without mental illness.

The community support movement of the 1970s ushered in a new era in the treatment of mental illness in the United States. Mental Health services in the era following deinstitutionalization have strongly followed a social support framework of intervention, attempting to formalize a model of peer support and increase social contact and engagement by increasing social network resources. During that time, mental health policy in the U.S. utilized informal social networks and support systems as resources for mental health patients transitioning into the community following long-term hospitalization. From a policy and services standpoint, less reliance on formal professional support systems and services helped to contain costs associated with providing a continuum of care. In 1977, the National Institute of Mental Health developed one of the first national initiatives to utilize the social network research and psychosocial rehabilitation services began assisting persons with chronic mental illness with housing, daily living skills, employment and socialization opportunities (Turner \& TenHoor, 1978). 
As part of the shift from institutional care to community based care, the concept of recovery from a serious mental illness has become a reality for many individuals and their families. However, the social cost of deinstitutionalization resulted in many people returning to homes where they were unwanted or to families who were unable to care for them. To stave off the isolation and stigma often associated with mental illnesses such as Schizophrenia or Bipolar disorder, individuals began congregating and creating support groups to buffer the transition back into society. This resulted in the creation of small communities of support. Today, mental health programs that intentionally bring similar people together to share experiences, provide support, and facilitate skill development are referred to as intentional recovery communities. Intentional communities were founded on the principle of consumersurvivors providing mutual support to help each other reintegrate into the community following long-term hospitalization from a serious mental illness. Building an intentional community based on the value of recovery serves as the foundation of the intentional recovery community of the clubhouse (Herman, Onaga, Pernice-Duca, et al., 2005).

Many of the intentional communities found in the U.S. and abroad include the psychosocial rehabilitation model (a.k.a Clubhouse), which acknowledges the influence of the group in hastening recovery from serious mental illness (Pernice-Duca \& Onaga, 2009). To date, there are over 300 clubhouse programs worldwide (www.iccd.org). As of 2011, the U.S. Substance Abuse and Mental Health Services Administration (SAMSHA) has listed the Clubhouse Model on the National Registry of Evidence-Based Practices and Programs (NREPP) clubhouses (http:// www.nrepp.samhsa.gov/)

\section{Intentional recovery communities for addiction and mental illness}

\subsection{2-step peer support groups}

Peer support groups have been in existence for several decades but, by far, the best-known modality is the 12-Step Model (Alcoholics Anonymous, 2001). Formed under the principal that one alcoholic helping another could bring about lasting change and that "faith without works is dead" (AA: Alcoholics Anonymous, 4th Ed., 2001, pp. 76), the 12-steps of Alcoholics Anonymous have become synonymous with recovery support groups. Started in 1935 by former New York stockbroker Bill Wilson and medical doctor Bob Smith, AA took root in Akron, Ohio after Wilson, an alcoholic struggling against taking a drink while on a business trip, reached out to Smith - an acknowledged alcoholic also battling the disease (Kurtz, 1979). Wilson and Smith employed principals founded by U.S. temperance organizations like the Emmanuel Movement and the Oxford Group as an early blueprint for AA, but it was Wilson's experience with Rowland H., an alcoholic treated by Carl Jung in Zurich, that provided what he described as "the foundation stone upon which our society has been built" (Schoen, 2009, pp. 10). Jung believed that chronic alcoholism was, in essence, a "spiritual thirst (for a) union with god" (Schoen, 2009, pp. 18). In his transmissions with Wilson, Jung invoked the ancient aphorism: spiritus contra spiritum which, loosely translated, suggests that one spirit "drives out" the other (Miller \& Bogenschutz, 2007, pp. 433). Employing Jung's philosophy, Wilson moved away from the strictly Christian theological underpinnings of the Oxford Group and into a concept that emphasized personal responsibility and an individualized interpretation of a "power greater than ourselves (Alcoholics Anonymous, 2004, p. 59)".

Though recovery, from a 12-Step perspective, is phenomenological (as evidenced by AA sayings like "Recovery is an inside job"), the emphasis is on the power of the group. As the first tradition of AA states: "Personal recovery depends on AA unity" (Alcoholics 
Anonymous, 1953, pp. 129). Though 12-Step concepts are still scrutinized by many scientific concerns due to a dearth of empirical evidence (Fiorentine, 1999), they constitute the treatment model of choice in most rehabilitation facilities and serve as the foundation for other self-help groups -- Debtors Anonymous, Overeaters Anonymous and Gamblers Anonymous among them. The largest and most popular program in the world for people wishing to recover from alcoholism (Tongin, Connors and Miller as cited in Barbor \& Del Boca, 2010), much of AA's success may rest in its adherence to what has since been described by Irving Yalom as the 12 "therapeutic factors" of group psychotherapy (Yalom \& Leszcz, 2005). The group session is seen as information-sharing and, as a process, includes a number of these factors; namely imparting of information, installation of hope, group cohesion, catharsis (sharing has no consequences and can be extremely emotional), imitative behavior (those with long-term sobriety are often revered by peers and their aphorisms passed on to other groups and members), interpersonal learning (the exchange between members that occurs both inside and outside of the group environment) and self-understanding. Perhaps its most salient therapeutic factor is altruism. The essence of the $12^{\text {th }}$ step, which asks that recovering alcoholics "carry the message" to others who still suffer (Alcoholics Anonymous, $4^{\text {th }}$. Ed., 2004, pp. 60), is an essential part of the process and a key factor in the proliferation of AA and other 12-Step organizations. While there is significant empathy within the fellowship, altruism seems to be the factor that brings about the most lasting change. As the saying goes "We can only keep what we have by giving it away" (personal communications, AA and NA meetings, 1995-2010). With no governing forces and employing only administrative service workers, AA, as an institution, relies solely on the desire of its members to congregate and share their experiences. This intentionality places the responsibility of recovery squarely on the individual, but emphasizes the power of the group in terms of providing support.

\subsection{The clubhouse}

Approximately 7.5 million Americans belong to as many as 1.5 million self-help groups (Lieberman \& Snowden, 1994). Consumers often report joining peer support programs for social support, such as seeing friends, feeling a sense of family, socializing, and exchanging ideas (Mowbray \& Tan, 1992). The power and influence social support provides to overall mental well being is not surprising given that humans are a social species meant to live in groups and not in isolation (Weisfeld, 1999). Thus it is apropos that a group of patients that had recently been discharged from a state psychiatric facility banded together to form a support group known as "We are not alone" or WANA. In the 1950's with the assistance of more volunteers, the group became known as the Fountain House which became the template for the development of Clubhouses (Anderson, 1998).

The clubhouse program, which is based on psychosocial psychiatric rehabilitation principles rather than a medical model of treatment, values social relationships and social participation as an active agent of rehabilitation and recovery (Mastboom, 1992). The specific psychiatric rehabilitation environment of the clubhouse is guided by a philosophical orientation reflecting consumer empowerment, competency, community, and recovery (Beard, Propst, \& Malamud, 1982;Pernice-Duca, 2009; Warner et al., 1999). These orientations are operationalized in the clubhouse setting through shared decision-making, skill training, and vocational services. The clubhouse program however, can also been described as an exemplary model of the operant-environment (O-E) interaction found in human ecosystems. From this perspective, the social environment creates an atmosphere in which change is possible and interactions within the environment serve to enhance quality of life and hasten 
the recovery process. However, the O-E interaction is limited and does not explain the humanistic qualities of the social environment. Clubhouses have been designed to increase social connections for individuals with little family or social network ties (Beard, 1992b). Further, they have also been cited as catalysts to recovery in the narratives of clubhouse members (Beard, 1992b; Ely, 1992; Deegan, 1988; Paul, 1992; Peckoff, 1992).

A key component of the Clubhouse psychiatric rehabilitation program is to establish or maintain social relationships. Clubhouses offer individuals opportunities to meet new friends to expand personal networks, as well as to identify themselves as someone other than a person living with mental illness (Macias \& Rodican, 1997). Four fundamental principles guide clubhouse programs: (a) the clubhouse belongs to its members, (b) daily attendance is desired and makes a difference to other members, (c) members feel wanted as contributors, and (d) members feel needed (Beard, Propst, \& Malamud, 1982). Clubhouse programs offer a range of community supports such as housing assistance, employment training and placement, and self-help resources. The clubhouse model has an egalitarian social structure with members and staff sharing in clubhouse work and decision-making. The central tenet of the clubhouse model is what is known as the "work-ordered day." It mimics a normal workday in that the day begins at 9:00 A.M. and essentially ends at 5:00 P.M., with social activities and support groups occurring after hours. The work-ordered day is designed to provide individuals with a workday structure that incorporates work ethics and social skills needed to prepare one for community reintegration. Clubhouse members work side-by-side along with clubhouse staff, interacting through the work-ordered day activities. Clubhouse participants are referred to as "members," and membership is voluntary.

The clubhouse was designed to address the needs of people living with chronic or persistent mental illness who have encountered losses in social skills, friendships, family connections, and employment (Mastboom, 1992). As a rehabilitation program, clubs assist people in leading more productive, community oriented lives by encouraging skill development within an environment that supports them to meet the demands of daily living, socialization, and employment (Anthony, Cohen, Farkas, \& Gagne, 2002).

According to Beard, Propst, \& Malmund (1982), social interaction is an important aspect of the program. These authors assert that members "feeling needed" is one of the three core elements of the clubhouse model. Therefore, it is contended that through clubhouse participation, members gain a sense of connection with others, thereby reducing isolation while increasing social ties. Further, members also elicit support from their social support networks and engage in mutually supportive reciprocal interactions with network supports. Clubhouse members make use of the clubhouse model in the purpose of creating change in their lives, specifically in forming significant relationships, promoting educational and employment aspirations and improving one's social life (Norman, 2006). Members adopt the philosophy that the dissimilarities among peers are a resource rather than a limitation. This philosophical and relational attitude has been found to be important in creating a supportive, intentional recovery community.

\subsection{Peer-run drop-in centers}

Peer-run drop-in centers, or consumer operated services (COPS), are services planned, operated, administered and evaluated by people who have a psychiatric disability (SAMHSA, 1998) or those who utilize mental health services. Peer delivered services are services provided by individuals who identify themselves as having a mental illness and deliver services for the primary purse of helping others with mental illness (Solomon, 2004). 
Non-consumers may be involved in the service or program, but their inclusion is within the control of consumers. A primary consumer is a direct recipient of mental health services either public or private. Peer programs are peer-driven, peer-run and peer-operated. They give people choices, decision-making roles, and positions of authority. Successful peerdelivered services are based on the values of equality and respect, encourage active participation by primary consumers, and offer support of consumer autonomy in services delivered. Programs are based on the values of empowerment, self-determination, acceptance and support. Peer support programs and services rely on experiential knowledge gained by the personal experience of having a psychiatric disability.

The President's New Freedom Commission for Mental Health in the U.S. (2003) advocated for a shift in resources to a recovery-based model, including more consumer-run services and programs. The recovery orientation suggests that "adjuncts and alternatives to formal treatment, involvement of self-help groups, and social opportunities at local drop-in centers foster empowerment and provide opportunities for a more meaningful life (Forquer \& Knight, pg. 25)." These peer-run programs provide consumers opportunities to learn and share coping skills and strategies and move into more active assistance and away from passive patient roles, and build/or enhance self-esteem, and self confidence. Peer delivered or consumer-run programs may include peer-operated drop-in centers, peer-run crises centers, housing programs, peer counseling, peer case-management, advocacy training, and peer support self-help groups.

The peer-operated drop-in center concept originated as a response to the lack of inclusive options in the community. It began as friends helping friends and is based on the value that all individuals deserve to be treated as human beings with rights, respect, and dignity, and to have the opportunity to live their lives in the community. Drop-in centers are a form of peer-support. They are run by primary consumers that provide mutual, social, emotional, and instrumental support to those who share a mental health condition. Drop-in centers have some paid staff and a significant number of volunteers and services are embedded within a formal organization as a freestanding legal entity. The concept of voluntary attendance and participation remains one of the primary attributes of any drop-in center. Drop-in centers serve as an important outreach access point and welcoming place for consumers who want to benefit from peer-delivered services but may choose to not be part of a traditional clinical milieu. Drop-in centers are places that are free from therapy, formal skills training, and clinical supervision. They provide an informal, supportive, intentional community to assist in the recovery process. These recovery experiences may include opportunities to learn and share coping skills and strategies with fellow peers. Peers serve as role models to others with psychiatric disabilities; they are able to navigate through systems and advocate for others who share the disability based on their own experiences. Knowing peers who are successfully coping with their illness leads to more hopefulness and optimism (Saltzer \& Liptzin-Shear, 2002).

\section{Conclusion}

Recovery occurs among many people suffering with serious mental illness (Corrigan \& Ralph, 2005; Davidson, et al., 2007; Onken, Craig, Ridgway, Ralph, \& Cook, 2007). The drive to pursue a greater understanding of the potential for recovery from serious mental illness emerged from consumers of mental health and psychiatric services, public health policies, and data from longitudinal studies. Also, consumers of mental health services have become more vocal and active in the treatment and care they receive, thus inspiring a movement in the delivery of psychiatric services to attend to consumer strengths, natural supports, and decrease social 
isolation (Davidson, et al., 2007; Drake, 2005; Resnick, Fontana, Lehman, \& Rosenheck, 2005). Psychosocial rehabilitation programs provide numerous services including self-help and mutual-help groups, community residential services, peer run drop-in services, supported education and employment services, and clubhouses (Lucca \& Allen, 2001). Research has identified the benefits of many of these programs in providing effective treatment for individuals with serious mental illness. For example, self-help groups have been found to increase social support, and create a sense of belonging, and a sense of empowerment (Hardiman \& Segal, 2003). Approximately 7.5 million Americans belong to as many as 1.5 million self-help groups (Lieberman \& Snowden, 1994). Consumers often report that joining peer support drop-in centers provide opportunities for social support, such as seeing friends, feeling a sense of family, socializing, and exchanging ideas (Mowbray \& Tan, 1992). Identifying with a group may act as a shield in protecting individuals form stigma (Karidi, et al., 2010), improving quality of life and improving social relationships (Schonebaum, et al., 2006).

\section{References}

Abrahms, S. (July-August, 2011). Homeless no more. AARP bulletin, 52(6),12-15.

Accordino, M. P., \& Hunt, B. (2001). Family Counseling Training in Rehabilitation Counseling Programs Revisited. Rehabilitation Education, 15(3), 255-264.

Alcoholics anonymous (2004). Alcoholics anonymous (4th ed.). New York, NY: Alcoholics Anonymous World Services, Inc.

Alcoholics Anonymous (2002). Twelve steps and twelve traditions. New York, NY: Alcoholics Anonymous WorldS ervices, Inc.

Anderson, S. (1998). We are not alone: Fountain House and the development of clubhouse culture. New York, NY: Fountain House.

Anthony, W. A. (1993). Recovery from mental illness: The guiding vision of the mental health service system in the 1990s. Psychosocial Rehabilitation Journal, 16(4), 11-23.

Anthony, W. A., Rogers, E. S., \& Farkas, M. (2003). Research on evidence-based practices: Future directions in an era of recovery. Community Mental Health Journal, 39(2), 101- 114.

Beard, J. H., Propst, R. N., \& Malmund, T. J. (1982). The fountain house model of psychiatric rehabilitation. Psychosocial Rehabilitation Journal, 5(1), 1-13.

Beale, V., \& Lambric, T. (1995). The recovery concept: Implementation in the mental health system. Ohio Department of Mental Health, 1-20, p. 5.

Biegel, D. E., McCardel, E., \& Mendelson, S. (1985). Social networks and mental health: An annotated bibliography. Beverly Hills, CA: Sage Publications.

Bellack, A.S. (2006). Scientific and consumer models of recovery in schizophrenia: Concordance, contrasts, and implications. Schizophrenia Bulletin, 32(3), 432-442.

Berkman, L. F. (1995). The role of social relations in health promotion. Psychosomatic Medicine, 57(3), 245-254.

Berkman, L. F., Glass, T., Brissette, I., \& Seeman, T. E. (2000). From social integration to health: Durkheim in the new millennium. Social Science \& Medicine, 51(6), 843-857

Brewer, P., Gadsden, V., \& Scrimshaw, K. (1994) The community group network in mental health: A model for social support and community integration. British Journal of Occupational Therapy, 57(12), 467-70.

Brissette, I. Cohen, S., \& Seeman, T. E. (2000). Measuring social integration and social networks. In S. Cohen, L. Underwood \& B. Gottlieb (Eds.), Support measurements and interventions: A guide for social and health scientists. NY: Oxford Press. 
Calabrese, J. D., \& Corrigan, P. W. (2005). Beyond Dementia Praecox: Findings From LongTerm Follow-Up Studies of Schizophrenia. In R. O. Ralph, P. W. Corrigan, R. O. Ralph, P. W. Corrigan (Eds.), Recovery in mental illness: Broadening our understanding of wellness (pp. 63-84). Washington, DC US: American Psychological Association.

Carolan, M. Onaga, E.O., Pernice-Duca, F., \& Jimenz, T. (2011). A Place to Be: The Role of Clubhouse in Facilitating Social Support. Psychiatric Rehabilitation Journal, 35(2), 125- 132

Clay, S. (2005). About Us: What we have in common. In S.Clay, B. Schell, P. Corrigan, \& R. O. Ralph(Eds.) On our own, Together: Peer program for people with mental illness. Vanderbilt University Press.

Caron, J., Tempier, R., Mercier, C., \& Leouffre, P. (1998). Components of social support and quality of life in severely mentally ill, low income individuals and a general population group. Community Mental Health Journal, 34(5), 459-475.

Coatsworth-Puspoky, R. R., Forchuk, C. C., \& Ward-Griffin, C. C. (2006). Peer support relationships: An unexplored interpersonal process in mental health. Journal of Psychiatric and Mental Health Nursing, 13(5), 490-497.

Corrigan, P. (2002). Empowerment and serious mental illness: Treatment partnerships and community opportunities. Psychiatric Quarterly, 73(3), 217-228.

Corrigan, P.W., Giffort, D., Rashid, F., Leary, M., \& Okeke, I. (1999). Recovery as a psychological construct. Community Mental Health Journal, 35(3), 231-239.

Corrigan, P.W., \& Phelan, S. M. (2004). Social support and recovery in people with serious mental illnesses. Community Mental Health Journa,l 40(6), 513-523.

Corrigan, P.W., \& Ralph, R.O. (2005) Recovery in Mental Illness: Broadening Our Understanding of Wellness, (pp3-17). Washington DC: American Psychological Association, p. 282.

Davidson, L., Borg, M., Marin, I., Topor, A., Mezzina, R., \& Sells, D. (2005). Process of recovery in serious mental illness: Findings from a multinational study. American Journal of Psychiatric Rehabilitation, 8, 177-201.

Davidson, L., Hoge, M.A., Merrill, M.E., Rakfeldt, J., \& Griffith, E.E.H. (1995). The experiences of long-stay inpatients returning to the community. Psychiatry: Interpersonal and Biological Processes, 58 (2), 122-132.

Davidson, L., O'Connell, M., Tondora, J., Styron, T., \& Kangas, K. (2006). The top ten concerns about recovery encountered in mental health system transformation. Psychiatric Services, 57(5), 640-645.

Davidson, L., \& Roe, D. (2007). Recovery from versus recovery in serios mental illness: One strategy for lessening confusion plaguing recovery. Journal of Mental Health, 16(4), 459-470.

Davidson, L., Tondura, J., O'Connell, M., Kirk Jr., T., Rockholz, \& Evans, A. (2007). Creating a Recovery-Oriented system of behavioral health care: Moving from concept to reality. Psychiatric Rehabilitation Journal, 31(1), 23-31.

Deegan, P. E. (1988). Recovery: The lived experience of rehabilitation. Psychosocial Rehabilitation Journal, 11(4), 11-19.

Deegan, G. (2003). Discovering recovery. Psychiatric Rehabilitation Journal, 26(4), 368-376.

DeSisto, M., Harding, C. M., McCormick, R. V., Ashikaga, T., \& Brooks, G. W. (1995a). The Maine and Vermont three-decade studies of serious mental illness. II. Longitudinal course comparisons. British Journal of Psychiatry, 167, 338-342.

Drake, R. E. (2005). How evidence-based practices contribute to community integration: A commentary on Bond et al. Community Mental Health Journal, 41(1), 87-90. 
Durkheim, E. (2001). Suicide: A study in sociology. In E. S. Shneidman (Ed.), Comprehending suicide: Landmarks in 20th-century suicidology (pp. 33-47). Washington, DC US: American Psychological Association.

Fairweather, G.W. \& Onaga, E.O. (1993). Empowering the mentally ill. Austin, TX: Fairweather Publishing.

Fiorentine, R. (1999). After drug treatment: Are 12-step programs effective in maintaining abstinence? The American Journal of Drug and Alcohol Abuse, 25(1), 93-116.

Fisk, D., Rowe, M., Laub, D., Calvocoressi, L., \& DeMino, K. (2000). Homeless Person With Mental Illness and Their Families: Emerging Issues from Clinical Work. Families in Society, 81(4), 351-359.

Forquer, S. and Knight, E. (2001). Managed care: Recovery enhancer or Inhibitor? Psychiatric Services 52(1), 25-26.

Froland, C., Brodsky, G., Olson, M., \& Stewart, L. (2000). Social support and social adjustments: Implications for mental health professionals. Community Mental Health Journal, 36(1), 61-75.

Goldberg, R. W., Rollins, A. L., \& Lehman, A. F. (2003). Social network correlates among people with psychiatric disabilities. Psychiatric Rehabilitation Journal, 26(4), 393-402.

Green, G., Hayes, C., Dickinson, D., Whittaker, A., \& Gilheany, B. (2002). The role and impact of social relationships upon well-being reported by mental health service users: A qualitative study. Journal of Mental Health, 11(5), 565-579.

Hardiman, E. R., \& Segal, S. P. (2003). Community membership and social networks in mental health self-help agencies. Psychiatric Rehabilitation Journal, 27(1), 25-33.

Harding, C. M., Brooks, G. W., Ashikaga, T., \& Strauss, J. S. (1987a). The Vermont longitudinal study of persons with severe mental illness: I. Methodology, study sample, and overall status 32 years later. The American Journal of Psychiatry, 144(6), 718-726.

Harding, C. M., Brooks, G. W., Ashikaga, T., \& Strauss, J. S. (1987b). The Vermont longitudinal study of persons with severe mental illness: II. Long-term outcome of subjects who retrospectively met DSM-III criteria for schizophrenia. The American Journal of Psychiatry, 144(6), 727-735.

Hatfield, A. B., \& Lefley, H. P. (1993). Surviving mental illness: Stress, coping and adaptation. New York, NY: The Guilford Press.

Hatfield, A. B., \& Lefley, H. P. (1987). Families of the mentally ill: Coping and adaptation. New York, NY: The Guilford Press.

Herman, S. E., Onaga, E., Pernice-Duca, F., Oh, S., \& Ferguson, C. (2005). Sense of community in clubhouse programs: Member and staff concepts. American Journal of Community Psychology, 36(3/4), 343-356.

Hogan, M. F. (2003). The President's New Freedom Commission: Recommendations to Transform Mental Health Care in America. Psychiatric Services, 54(11), 1467-1474.

House, J. S., Landis, K. R., \& Umberson, D. (1988). Social relationships and health. Science, 241, 540-545.

Karidi, (2010). Perceived social stigma, self-concept, and self-stigmatization of patient with schizophrenia. Comprehensive psychiatry, 51(1), 19.

Kawachi, I. \& Berkman, L. F. (2001). Social ties and mental health. Journal of Urban Health: Bulletin of the New York Academy of Medicine, 78(3), 458-467.

Kelly, M. \& Gamble, C. (2005). Exploring the concept of recovery in schizophrenia. Journal of Psychiatric Mental and Mental Health Nursing, 12, 245-251. 
Kurtz, E. (1979). Not-god: A history of alcoholics anonymous. Center City, MN: Hazelden Foundation.

Landrine, H. (1992).Clinical implications of cultural differences: The referential versus the indexed self. Clinical Psychology Review, 12, 401-415.

Lieberman, M. A., \& Snowden, L. R. (1993). Problems in assessing prevalence and membership characteristics of self-help group participants. Journal of Applied Behavioral Science, 29, 166-180.

Lin, N., Ye, X., \& Ensel, W. M. (1999). Social support and depressed mood: A structural analysis. Journal of Health and Social Behavior, 40(4), 344-359.

Littrell, J. \& Bech, E. (2001). Predictors of depression in a sample group of African-American homeless men: Identifying effective coping strategies given varying levels of daily stressors. Community Mental Health Journal, 37(1), 15-29.

Macias, C., \& Rodican, C. (1997). Coping with recurrent loss in mental illness: Unique aspects of clubhouse communities. Journal of Personal and Interpersonal Loss, 2, 205221.

Mastboom, J. (1992). Forty clubhouses: Model and practices. Psychosocial Rehabilitation Journal, 16(2), 9-23.

Mead, S., Hilton, D., \& Curtis, L. (2001). Peer support: A theoretical perspective. Psychiatric Rehabilitation Journal, 25(2), 134-141.

Miller, W. R., \& Bogenshutz, M. P. (2007). Spirituality and addiction. Southern Medical Journal, 100(4), 433-436.

Mowbray, C., \& Tan, C. (1992). Evaluation of an innovative consumer run service model: The drop in center. Innovation and Research, 1(2), 33-42.

National Institue of Mental Health (2010). Questions and answers of about the national comorbidity survey replication (NCSR) study. Retrieved from

http:/ / www.nimh.nih.gov/health/topics/statistics/ncsr-study/questions-andanswers-aboutthenational-comorbidity-survey-replication-ncsr-study.shtml\#q8

National Institute of Mental Health. (2010). The Numbers count: Mental disorders in America.Retrieved from:

http:/ / www.nimh.nih.gov/health/publications/the-numbers-countmentaldisorders-in-america/index.shtml\#Intro

Nelson G, Lomotey J. (2006). Quantity and quality of participation and outcomes of participation in mental health consumer-run organizations. Journal of Mental Health 15(1):63-74.

Norman C. The Fountain House movement, an alternative rehabilitation model for people with mental health problems, members' descriptions of what works. Scandinavian Journal of Caring Sciences. 2006;20(2):184-192.

Onken, S. J., Craig, C. M., Ridgway, P., Ralph, R. O., \& Cook, J. A. (2007). An analysis of the definitions and elements of recovery: A review of the literature. Psychiatric Rehabilitation Journal, 31(1), 9-22.

Perese, E. F., Getty, C., \& Wooldridge, P. (2003). Psychosocial club members' characteristics and their readiness to participate in a support group. Issues in Mental Health Nursing, 24, 153-174.

Pernice-Duca, F. M. (2008). The structure and quality of social network support among mental health consumers of clubhouse programs. Journal of Community Psychology, 36(7), 929-946. 
Pernice-Duca, F., \& Onaga, E. (2009). Examining the contribution of social network support to the recovery process among clubhouse members. American Journal of Psychiatric Rehabilitaion, 12, 1-30.

Ralph, R. (Ed.), \& Corrigan, P. (Ed.). (2005). Recovery in mental illness: Broadening our understanding of wellness. Washington, DC US: American Psychological Association. doi:10.1037/10848-000

Resnick, S. G., Fontana, A., Lehman, A. F., \& Rosenheck, R. A. (2005). An empirical conceptualization of the recovery orientation. Schizophrenia Research, 75(1), 119-128.

Ridgway, P. (2001). ReStorying psychiatric disability: Learning from first person recovery narratives. Psychiatric Rehabilitation Journal, 24(4), 335-343.

Salzer, M. S., \& Shear, S. (2002). Identifying consumer-provider benefits in evaluations of consumer-delivered services. Psychiatric Rehabilitation Journal, 25(3), 281-288.

Schonebaum AD, Boyd JK, \& Dudek KJ. (2006). A comparison of competitive employment outcomes for the clubhouse and PACT models. Psychiatric Services (Washington, D.C.). 57(10), 1416-20.

Soloman, P. (2004). Peer support/peer provided services underlying processes, benefits and critical ingredients. Psychiatric Rehabilitation Journal, 27(4), 392-401.

Stahler, G. J., Shipley, T. F., Bartelt, D., DuCette, J. P. \& Shandler, I. W. (1995). Evaluating alternative treatments for homeless substance-abusing men: Outcomes and predictors of success. Journal of Addictive Diseases. 14(4), 151-167.

Tempier, R., Caron, J., Mercier, C., \& Leouffre, P. (1998) Quality of life of severely mentally ill individuals: A comparative study. Community Mental Health Journal 34, 477-486

Tongin, J. S., Connors, G. J., \& Miller, W. (2010). Treatment matching in alcoholism. In Barbor, T., \& Del Boca, F. K. (Eds.), International Research Monographs in the Addictions. New York, Turner, J. C., \& TenHoor, W. J. (1978). The NIMH Community Support Program: Pilot approach to a needed social reform. Schizophrenia Bulletin, 4(3), 319-348. NY: Cambridge University Press.

Turner, J. C., \& TenHoor, W. J. (1978). The NIMH Community Support Program: Pilot approach to a needed social reform. Schizophrenia Bulletin, 4(3), 319-348.

U.S. Department of Health and Human Services, Substance Abuse and Mental Health Services Administration, Center for Mental Health Services (2006). National consensus statement on mental health recovery. Washington, D.C.

Verhaeghe, M., et. al., (2008). Stigmatization and Self-Esteem of Persons in Recovery from Mental Illness: The Role of Peer Support. The International Journal of Social Psychiatry 54 (3), 206-18.

Whitaker, R. (2002). Mad in America: Bad science, bad medicine, and the enduring mistreatment of the mentally ill. Cambridge, MA US: Perseus Publishing.

Wilson, M., Flanagan, S., \& Rynders, C. (1999). The FRIENDS program: A peer support group model for individuals with a psychiatric disability. Psychiatric Rehabilitation Journal, 22(3), 239-247.

Yalom, I. D., \& Leszcz, M. (Col). (2005). The theory and practice of group psychotherapy (5th ed.). New York, NY US: Basic Books

Young, S. L., \& Ensing, L. S. (1999). Exploring recovery from the perspective of people with psychiatric disabilities. Psychiatric Rehabilitation Journal, 22(3), 219-231. 




\author{
Mental IIInesses - Evaluation, Treatments and Implications \\ Edited by Prof. Luciano LAbate
}

ISBN 978-953-307-645-4

Hard cover, 476 pages

Publisher InTech

Published online 13, January, 2012

Published in print edition January, 2012

In the book "Mental Illnesses - Evaluation, Treatments and Implications" attention is focused on background factors underlying mental illness. It is crucial that mental illness be evaluated thoroughly if we want to understand its nature, predict its long-term outcome, and treat it with specific rather than generic treatment, such as pharmacotherapy for instance. Additionally, community-wide and cognitive-behavioral approaches need to be combined to decrease the severity of symptoms of mental illness. Unfortunately, those who should profit the most by combination of treatments, often times refuse treatment or show poor adherence to treatment maintenance. Most importantly, what are the implications of the above for the mental health community? Mental illness cannot be treated with one single form of treatment. Combined individual, community, and socially-oriented treatments, including recent distance-writing technologies will hopefully allow a more integrated approach to decrease mental illness world-wide.

\title{
How to reference
}

In order to correctly reference this scholarly work, feel free to copy and paste the following:

Francesca Pernice-Duca, Wendy Case and Deborah Conrad-Garrisi (2012). The Role of Intentional Communities to Support Recovery from Mental Illness, Mental IIInesses - Evaluation, Treatments and Implications, Prof. Luciano LAbate (Ed.), ISBN: 978-953-307-645-4, InTech, Available from:

$\mathrm{http}: / / \mathrm{www}$.intechopen.com/books/mental-illnesses-evaluation-treatments-and-implications/the-role-ofintentional-communities-to-support-recovery-from-mental-illness

\section{INTECH}

open science | open minds

\section{InTech Europe}

University Campus STeP Ri

Slavka Krautzeka 83/A

51000 Rijeka, Croatia

Phone: +385 (51) 770447

Fax: +385 (51) 686166

www.intechopen.com

\section{InTech China}

Unit 405, Office Block, Hotel Equatorial Shanghai

No.65, Yan An Road (West), Shanghai, 200040, China

中国上海市延安西路 65 号上海国际贵都大饭店办公楼 405 单元

Phone: +86-21-62489820

Fax: $+86-21-62489821$ 
(C) 2012 The Author(s). Licensee IntechOpen. This is an open access article distributed under the terms of the Creative Commons Attribution 3.0 License, which permits unrestricted use, distribution, and reproduction in any medium, provided the original work is properly cited. 